\title{
VA DE VUELTA: DISPOSITIVO LÚDICO-EDUCATIVO, PARA ABORDAR LA ALFABETIZACIÓN DIGITAL DE NIÑOS Y NINIAS. SITUADO EN LA CULTURA QOM DE LA CIUDAD DE ROSARIO. SANTA FE. ARGENTINA
}

\section{VA DE VUELTA: PLAYFUL-EDUCATIONAL DEVICE, TO ADDRESS DIGITAL LITERAGY OF CHILDREN. APPLIED IN THE QOM GULTURE IN ROSARIO CITY. SANTA FE. ARGENTINA.}

\author{
MARÍA ROSA VAZQUEZ \\ Directora en VDV \\ Productora de Servicios Educativos \\ Guatemala 1385. Argentina. 2000 Rosario. \\ + 5493416060345 \\ vadevueltavdv@gmail.com
}

\section{PALABRAS CLAVES}

Patrimonio Cultural, Red Socio Técnica, Interculturalidad, Dispositivo LúdicoEducativo
KEY WORDS

Cultural Heritage, Social -Technical

Network Partner, Inter-cultural, Playful-

Educational Device. 


\section{Resumen}

Disponernos a interactuar con otra cultura, es en principio, reconocerla diferente a la nuestra.

Otra cultura, otras costumbres, otros símbolos, otros significantes.

¿Cuáles son los significados propios de cada cultura, que se resignifican sinérgicamente en este encuentro? ¿En una misma ciudad? ¿En una misma escuela?

Abordaremos el presente interrogante utilizando como metodología la observación participante, y como recurso "Va de Vuelta" Dispositivo Lúdico-Educativo.

"Va de Vuelta", diseñado por María Rosa Vazquez, se presentó en 2016 como la respuesta a una necesidad en las aulas del Siglo XXI, esto es: la aproximación a la alfabetización digital de niños y niñas. En esa misma oportunidad se enfatizó la necesidad de situarlo en una institución cuyos objetivos comunes fuesen la apropiación de valores culturales identitarios.

En 2017 "Va de Vuelta" se sitúa en la Escuela Nro. 1333 "Nueva Esperanza", escuela de nivel primario, cuya modalidad es bilingüe. En ella conviven niños/niñas y maestros/ maestras representantes de la cultura Qom, provenientes del Monte Chaqueño, junto a niños/niñas, maestros/maestras nacidos en la ciudad de Rosario.

El presente trabajo escrito da cuenta de la potencia que el Dispositivo Lúdico-Educativo "Va de Vuelta" ofrece a las culturas que conviven en una misma institución escolar de nivel primario, favoreciendo la transmisión cultural a través del conocimiento de las artes y las costumbres identitarias.

El dispositivo consta de tres manifestaciones: un relato escrito e impreso en soporte papel, un juego de tablero físico para jugarlo en grupos, y un juego de tablero digital disponible para dispositivos con sistema operativo Android. 


\section{Abstract}

Being willing to interact with another culture, in principle, to recognize the difference from our own.

Another culture, other customs, other symbols, other expressions.

What are the characters of each culture, that are synergistically accommodated in this encounter? In the same city? In the same school?

We will approach this question using participant observation as methodology, and "Va de Vuelta" as a resource Playful-Educational Device.

."Va de Vuelta", designed by María Rosa Vazquez, was presented in 2016 as an answer to the XXI Century classrooms need, that is: the approach to digital literacy of children. At the same time, to address the need of an institution for a device whose common aims are the understanding of cultural identity values is emphasized.

In 2017 "Va de Vuelta" is being applied in School 1333 "Nueva Esperanza", a primary level school, whose modality is bilingual. Where children and teachers representing the Qom culture, coming from Monte Chaqueño (Province of Chaco, Argentina), live with children and teachers born in the city of Rosario.

This paper gives an account of the power that the "Va de Vuelta" Playful- Educational Device offers to the cultures that coexist in the same primary school institution, favoring cultural transmission through the arts and cultural identity.

The device consists of three components: a story printed on paper, a physical board game for group play, and a digital board game available on devices with Android operating system. 


\section{Introducción}

EI Siglo XXI nos obliga a incorporar tecnología digital en educación, sin olvidar que educar es un proceso que se inscribe en prácticas tradicionales que responden a una cultura colectiva. Los recursos didácticos utilizados en la educación tradicional se establecieron para la construcción de subjetividades basadas en soportes físicos: libros, juegos, juguetes. Tradicionalmente, los recursos didácticos han sido seleccionados o creados por los y las docentes, ajustándose a los lineamientos curriculares establecidos por el Ministerio de Educación. Crear recursos didácticos digitales supone un conocimiento y un equipo interdisciplinar que excede la formación y competencias docentes. Seleccionarlos es un proceso accesible.

En el recurso didáctico "Va de vuelta" situado en la cultura qom de la ciudad de Rosario, convergen la dimensión cultural, la dimensión institucional y la dimensión de los símbolos culturales inscriptos en los relatos infantiles. ¿Es "Va de vuelta" un recurso didáctico apropiado para ser aplicado en la Escuela Primaria Intercultural Bilingüe "Nueva Esperanza" de la ciudad de Rosario? El trabajo se aborda con el enfoque cualitativo, de paradigma interpretativo-simbólico.

\section{Objetivos}

Explorar la relación que establecen los y las docentes de primer ciclo de la Escuela Primaria Nro. 1333 "Nueva Esperanza" de Rosario con el recurso didáctico "Va de vuelta". Su objetivo específico es explorar la potencia que "Va de vuelta. Dispositivo Lúdico Educativo para abordar la alfabetización digital de niños y niñas. Situado en la cultura Qom de la ciudad de Rosario" tiene como recurso didáctico en Educación Intercultural Bilingüe qom-español.

\section{Metodología}

Adoptando un enfoque cualitativo, de paradigma interpretativo-simbólico (Pérez Serrano, 1994) la autora ha seguido lineamientos regidos por la observación participante. De esta manera, se ha ceñido, en primer lugar, a escuchar tanto a jóvenes, como adultos integrantes de la comunidad educativa intercultural bilingüe del barrio emplazado en Rouillón 4400, como también ha creado y presentado propuestas didácticas a niños, niñas y jóvenes en distintos contextos del Distrito Oeste de la ciudad de Rosario. El enfoque y la metodología adoptada, ha permitido comprender la dimensión de la importancia de los recursos didácticos en relación a los objetivos educativos, así como la dimensión de la complejidad que debe enfrentarse al diseñar un recurso didáctico intangible, un objeto digital, que se encuentre circunscripto en valores éticos y morales que la transmisión de cultura colectiva establece. 


\section{Dimensión espacio-temporal}

\subsection{La ciudad de Rosario.}

La ciudad de Rosario se caracteriza por su desarrollo cultural, y por sus actividades deportivas vinculadas al río Paraná. La oferta que la ciudad de Rosario tiene tanto para sus habitantes como para los turistas que la visitan es riquísima en diversidad de eventos culturales ${ }^{1}$ y recreativos ${ }^{2}$ : cine, teatro, paseos al aire libre por distintas rutas de senderos, bicicletas públicas disponibles en numerosas esquinas de la ciudad, recorridos a través del río Paraná en embarcaciones que cruzan hasta la isla "El espinillo". También puede disfrutarse de actividades gastronómicas de todo tipo: degustaciones de alimentos, cata de vinos y ferias de artesanos y huerteros que ofrecen sus productos manufacturados sin intermediarios.

Las actividades deportivas ofrecidas por los clubes ${ }^{3}$ asentados a la orilla del río Paraná, incluyen clases de canotaje, remo, natación a río abierto, windsurf, skysurf, entre otras.

Es especialmente destacable la relevancia que la infancia tiene para la ciudad de Rosario. Gracias a la gestión de la actual Ministra de Innovación y Cultura de la provincia de Santa Fe, Sra. María de los Ángeles González ${ }^{4}$, que ha puesto de relieve las infancias, ofreciéndoles el Tríptico de la Infancia ${ }^{5}$. El tríptico se compone de tres espacios físicos destinados a la recreación y estímulo de la creatividad de los niños y niñas rosarinos. Imaginar, crear, amar, volar, son algunos de los verbos que se conjugan en los recorridos que propone el Tríptico de la Infancia, enriquecido con la filosofía de juego libre del Pedagogo Italiano Francesco Tonucci.

En el escenario que ofrece la ciudad de Rosario, conviven rosarinos y rosarinas con la comunidad Qom, proveniente del Monte Chaqueño (Canal Encuentro, 2007). La ciudad de Rosario, a orillas del Río Paraná, se encuentra a $350 \mathrm{Km}$. de la Ciudad Autónoma de Buenos Aires, capital de la República Argentina. Con más de un millón y medio de habitantes, recibe desde hace aproximadamente sesenta años a descendientes del Pueblo Originario Qom.

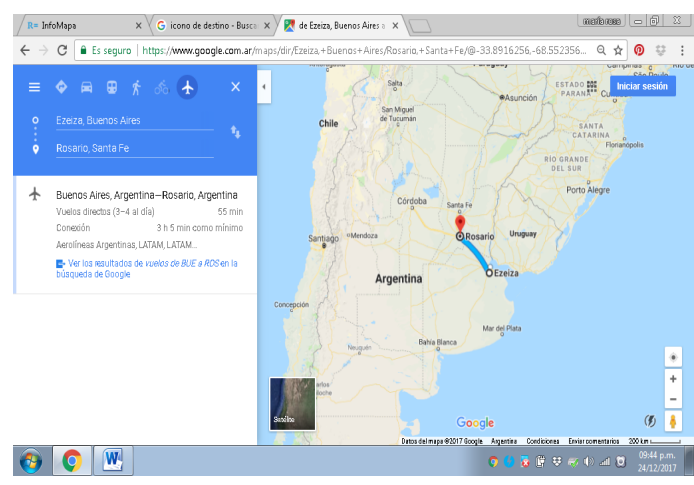

Figura $<1><$ Distancia Rosario-Buenos Aires $><$ Fuente: Google maps $>$ 
Si bien los primeros representantes llegaron a finales de la década de 1960, hoy, dentro de la comunidad, encontramos un numeroso grupo de nativos originarios de la provincia de Chaco, con otro grupo de descendientes que han nacido y crecido en la ciudad de Rosario. Aunque no existen datos actualizados sobre la cantidad de habitantes del Pueblo Originario Qom, los últimos registros determinan una cantidad total de $30.000^{6}$

Para logar una administración pública eficiente, la ciudad se ha organizado en seis Distritos En el siguiente mapa, se puede apreciar la división en Distritos:

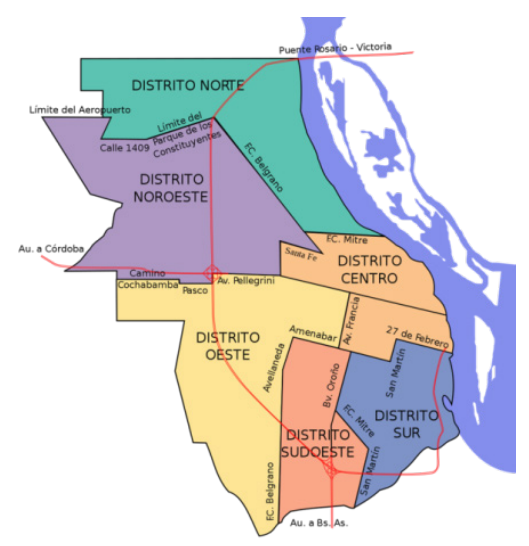

Figura $<2><$ División administrativa de la ciudad de Rosario $><$ Fuente: sitio web oficial de la Municipalidad de Rosario $>$

\subsection{La Escuela Primaria "Nueva Esperanza"}

El Distrito Oeste, indicado en el mapa con color amarillo [Fig.2] y la escuela Nro. 1333 "Nueva Esperanza" se indica con el ícono de destino indicado en color rojo. [Fig.3]

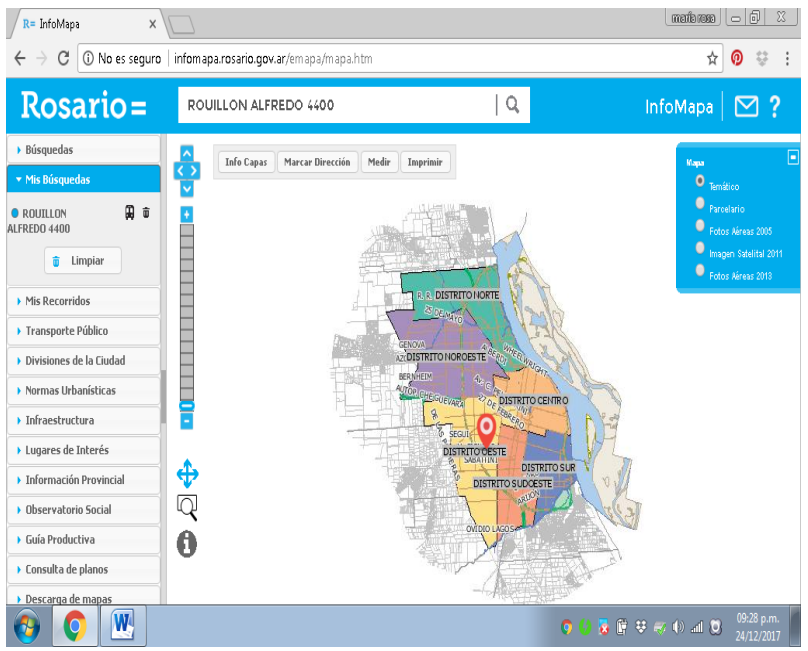

Figura $<3><$ Ubicación de la Escuela Nro. 1333 "Nueva Esperanza" $><$ Fuente: sitio web oficial de la Municipalidad de Rosario $>$ 
La escuela forma parte de las instituciones de educación pública incluidas en la Modalidad de Educación Intercultural Bilingüe ${ }^{7}$

\section{Dimensión Cultural}

\subsection{Interculturalidad en educación escolar}

(...) Existen dos concepciones de interculturalidad en el proceso educativo bilingüe. La primera se define como el manejo de dos o más códigos que posibilitan desenvolverse sin problemas en las respectivas culturas (...). La segunda como la ampliación del código de referencia mediante la adopción de elementos indispensables para afrontar los cambios inevitables que tienen lugar por el contacto o choque entre culturas así como por las dinámicas propias. (Bigot, 2007, p.223).

Sin olvidar que la institución escolar es un lugar de autoridad, que ha sido habitada con usos y costumbres monolingües, y por tanto monocultural, requiere, a partir de su denominación de Escuela Intercultural Bilingüe (EIB), adoptar las ideas eje de la Educación Intercultural Bilingüe en Latinoamérica. Estas ideas eje son:

"respeto de los derechos colectivos de los pueblos originarios, diálogo cultural entre iguales, refuerzo de las identidades indígenas, desarrollo de una autoestima positiva, revaloración de la lengua y la cultura, fomentar el uso de lenguas indígenas, consolidar el uso de la lengua materna indígena en la escuela, propiciar el aprendizaje de la segunda lengua, y desarrollar la competencia comunicativa, énfasis en basar la educación indígena en sus propios valores, pensamientos, cosmovisiones" (Bigot, 2007, p.224).

\subsection{Modalidad de Educación Intercultural Bilingüe}

La Constitución Nacional de la República Argentina, establece en el Artículo 14 que se garantizará el derecho a todos los ciudadanos de estudiar y aprender. Asimismo la Ley de Educación Nacional 26.206, en su Artículo 52 establece que "La Educación Intercultural Bilingüe es la modalidad del sistema educativo de los niveles de Educación Inicial, Primaria y Secundaria que garantiza el derecho constitucional de los pueblos indígenas (...) a recibir una educación que contribuya a preservar y fortalecer sus pautas culturales, su lengua, su cosmovisión e identidad étnica (...). Asimismo, la Educación Intercultural Bilingüe promueve un diálogo mutuamente enriquecedor de conocimientos y valores entre los pueblos indígenas y poblaciones étnica, lingüística y culturalmente diferentes, y propicia el reconocimiento y el respeto hacia tales diferencias"8.

Las Resoluciones Ministeriales de la Provincia de Santa Fe emitidas en 2017, reconocen a los establecimientos educativos de modalidad Intercultural Bilingüe, y aprueban un Ciclo de Formación docente para los maestros idóneos pertenecientes a la comunidad del Pueblo Originario Qom. Encontramos con fecha 
29 de Junio de 2017 la Resolución del Ministerio de Educación de la Provincia de Santa Fe Nro. 1188, en la que se resuelve la inclusión de la Escuela Primaria Nro. 1333, "Nueva Esperanza”, y la Escuela Secundaria Orientada Nro. 518 "Carlos Fuentealba”, entre otras, en la Modalidad de Educación Intercultural Bilingüe. Ambas escuelas se encuentran emplazadas en el mismo barrio. La primera en Garzón 4300 y la segunda en la calle Rouilón 4400, con apenas 400 metros de distancia entre una y otra.

Los maestros y maestras idóneas de la comunidad qom, tendrán acceso la profesionalización de su carrera docente, gracias a la Resolución de Ministerio de Educación de la Provincia de Santa Fe Nro. 1629 del 28 de Agosto de 2017, que aprueba un Ciclo de Formación Complementaria que otorgará un título de competencia docente Educador Intercultural Bilingüe Indígena (EIBI), favoreciendo así, el reconocimiento de sus competencias y el acceso y permanencia en el sistema educativo formal de la provincia de Santa Fe.

\subsection{La lingüística qom}

"Herman Parret señala dos concepciones diferentes en las teorías lingüísticas contemporánea: la “expresionista y la "articulista”" (Bigot, 2007, p.41) La primera se adjudica a Chomsky, en la cual el lenguaje es producto del sujeto que produce la idea. La segunda es postulada por Saussure, en la cual el pensamiento es una masa amorfa en la cual se establecen divisiones. De las relaciones entre esas divisiones de ideas y sonidos emergen los signos lingüísticos: significantes y significados.

En otra línea de pensamiento se encuentra Sapir, quien sostiene que la percepción de la realidad está mediatizada por el lenguaje, atribuyéndole al lenguaje el carácter de condicionante. Esta línea de pensamiento es recuperada por Margot Bigot (Bigot, 2007, p.42) quien advierte que para conocer las características de una cultura no basta con la simple observación. Es necesario, entonces, abordar el simbolismo lingüístico para que tales características sean comprendidas por la sociedad. Continúa su desarrollo exponiendo que en la producción lingüística de la cultura qom, la percepción y representación del espacio se correlaciona con la cultura originaria cazadora-recolectora. (Bigot, 2007, p.49)

Para producir comunicación de información, de ideas y sentimientos, debe existir una lengua: sistema de signos y un contexto sociocultural compartido: creencias. Esta comunicación construye procesos identitarios que permiten identificar a la comunidad que la comparte. Sin embargo, es en una situación de conflicto entre culturas, cuando cobra relevancia la relación entre las lenguas y los procesos identitarios. Una de las culturas en conflicto asumirá un rol dominante: sustituyendo, manipulando o estigmatizando a la cultura que asume un rol subalterno. (Bigot, 2007, p.53)

Frente a este conflicto, pueden identificarse comportamientos puestos en funcionamiento en forma consciente o inconsciente que modificarán la relación de la comunidad con su propia lengua. Entre estos comportamientos, que se asemejan a los de otras culturas aborígenes latinoamericanas se encuentran: 1)

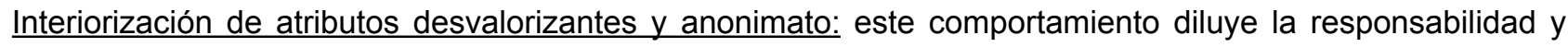


consiste en olvidar la lengua para mantener una situación confortable. 2) Positivización del estigma: este es un signo de toma de conciencia del hecho que la desvalorización es consecuencia de una situación de discriminación y dominación. 3) Instrumentalización: los integrantes de la cultura tienen conciencia de la desigualdad y sacan provecho de la situación para obtener algún beneficio: subsidios, empleos, entre otros. 4) Asimilación: este comportamiento consiste en rechazar a la cultura minoritaria a la cual se pertenece y unirse a la mayoritaria, aceptándose valores y normas de la cultura dominante. 5) La acción colectiva: es el comportamiento que revaloriza la singularidad, salvaguardando los lazos con la cultura de origen. Esta conducta adopta una actitud de idealización de su propio grupo, a la vez que es crítica respecto de la cultura dominante. (Bigot, 2007, pp. 53-54).

\section{Dimensión institucional}

\subsection{Rol del docente}

Disponerse a desempeñar el rol de educador en este Siglo XXI, en Argentina, supone un ejercicio que excede ampliamente la formación docente. Sin embargo, entre una gran cantidad de funciones que emergen de las necesidades de los contextos sociales de las poblaciones de cada institución escolar, se conserva una función académica relevante: la selección y/o creación de los recursos didácticos para ser aplicados en el aula de clases. Estos recursos deben cumplir numerosos requisitos de selección por parte de los y las docentes. El atractivo estético visual constituye uno de los requisitos fundamentales para lograr la atención sostenida de los educandos. Para los y las educadoras de niños y niñas, el requisito más importante es que tal recurso sea apropiado para presentar un conjunto de valores socialmente consensuados. A este conjunto de valores les llamamos contenidos curriculares o currículo.

La tarea de selección es sencilla cuando ya se conocen las características particulares de un grupo de niños y niñas. Se trata de una tarea de reflexión permanente sobre la acción propia en relación con el conjunto de niños y niñas, en un contexto socio-cultural e histórico en continuo movimiento.

\section{Dimensión del recurso didáctico}

\subsection{Los relatos como recurso subjetivante}

'La lectura de relatos, posibilita a quienes escuchan, imaginar los escenarios, identificarse con los protagonistas, desear una acción que represente las emociones experimentadas. De manera tal que estas acciones, posibiliten a su vez, los relatos en primera persona”. (Vazquez, 2014, p.1)

La Dra. Ana Blog aborda los nuevos escenarios escolares con un recurso tradicional: el relato. (Blog, 2009). Desde tiempos sin comienzo, los relatos han sido vehículos de transmisión de cultura identitaria. Todo 
relato requiere de un relator/ra, una persona que abre un espacio-tiempo en el cual es posible imaginar las escenas, los personajes y las circunstancias de la historia contada. El relator, la relatora, donan sus voces a un auditorio que no solo percibe sonidos, percibe significados, percibe valores, percibe una ética y una moral compartida por la comunidad. Los relatos son el recurso ancestral de transmisión de cultura identitaria.

\subsection{Símbolos culturales del Pueblo Originario Qom}

(...) El prototipo cazador ideal es aquel que mediante el abandono correlativo de las normas, implicado en el dominio de lo mágico, consigue reintegrarse en el universo en esencia real. El piogonak puede, por lo tanto, recuperar los rasgos de Nowet perdidos para siempre por la experiencia profana. Logra la entrada y salida de las reglas, el lenguaje y el dominio de los animales, las enfermedades y los espíritus, el vuelo mágico, la economía del daño y la salvación, la ubicuidad de las apariencias, el viaje al reino de los muertos y a otras regiones del universo. En tal forma, la cultura, en especial en sus aspectos más desacralizados, como la técnica y la economía, al margen de sus enlaces con el mundo animal, aparece como insuficiencia o carencia existencial que, como limitación inmanente, apenas merece ser afirmada y valorada. No es casual que solamente la apetencia del retorno a la condición shamánica, por la ruta que sea, logre conmoverlos profundamente a los indios. (Cordeu, 1969).

En los relatos ancestrales de la comunidad qom, las estrellas, los animales y la vegetación, han sido seres humanos que, en algún momento de sus vidas, se han transformado. Como consecuencia de esta creencia, algunas personas tienen la capacidad de escucharlos y hablar con ellos. A su vez, estas personas deben ser capaces de transmitir los diálogos mantenidos, al resto de la comunidad, de forma clara y sencilla.

Es entonces destacable que las categorías de clasificación del medio ambiente en "animado/inanimado" que se enseñan en las escuelas de la ciudad de Rosario y que responden a lineamientos del Ministerio de Educación de la Provincia de Santa Fe, no coinciden con los conceptos de la cultura qom. Este concepto “animado/inanimado" tiñe la bibliografía de enseñanza escolar disponible para nivel primario, así como también la Formación de Docentes del mismo nivel. Esta clasificación pertenece a una cultura que considera que gran parte de su medio ambiente carece de vida (derechos) y está subordinado a su voluntad. Ahora, es más sencillo comprender que posiblemente, la dificultad en el aprendizaje de la lecto-escritura en lengua española, para los niños y las niñas qom, no solamente responde a las dificultades fonológicas y sintácticas, sino, en gran medida al choque cultural que estos conceptos representan para su cosmovisión (Bigot, 2007, p. 230). 


\subsection{Estereotipos en los relatos de la cultura de rosarinos y rosarinas}

Una gran cantidad de relatos que los padres, madres, familias y docentes suelen contar a sus niños y niñas son aquellos en los cuales se puede identificar a un rey y una reina en un reinado. Una princesa, un príncipe y una acción de rescate por parte del príncipe, dirigiéndose a la princesa. Estos estereotipos de la personificación de la autoridad en los reyes, así como la debilidad de la princesa que requiere ser rescatada por el príncipe, habilitan la construcción de subjetividad basada en la desigualdad. Tanto los reyes detentando todo su poder sobre la vida y la muerte de los súbditos, como el mayor poder físico que el príncipe demuestra en los relatos para salvar a la princesa, son indicadores del valor que la sociedad otorga a la autoridad por encima de todo y de todos. Así como el menor valor que la mujer tiene en esa sociedad respecto del hombre.

Retomando el enfoque de los relatos como recursos subjetivantes, la Dra. Ana Blog nos invita a reflexionar sobre esos estereotipos socialmente aceptados, que invisibilizan situaciones de desigualdad y violencia de género, entre otras formas de violencia actual (Bloj, 2009).

\subsection{Recursos didácticos de pedagogía emprendedora}

La Pedagogía Emprendedora surge en el marco de la Propuesta Curricular de Jornada Ampliada ${ }^{9}$ para las escuelas primarias de la Provincia de Santa Fe.

Para comprender el marco en el cual se incorpora esta metodología emprendedora, necesitamos remitirnos al 2006, cuando la Dra. María de los Ángeles González asume la conducción de la Secretaría de Cultura de la Municipalidad de Rosario. Los rosarinos y rosarinas nos referimos a la Dra. González, actualmente Ministra de Innovación y Cultura de la Provincia de Santa Fe, por su apodo, Chiquit Los niños y niñas encuentran en Rosario espacios de juego y recreación concebidos desde la mirada de las infancias de sus padres y sus abuelos. El rescate de usos y costumbres de cultura identitaria vinculada a los oficios, las costumbres cotidianas de los rosarinos y rosarinas descendientes de comunidades europeas que han encontrado en esta ciudad, un lugar en el mundo donde es posible volver a comenzar, los espacios verdes, los animales de la granja, componen la escena del Tríptico de la Infancia ${ }^{5}$

Desde el Ministerio de Innovación y Cultura la Dra. González ha generado la Propuesta Curricular de Jornada Ampliada ${ }^{10}$ junto al Ministerio de Educación. Uno de los objetivos de la Jornada Ampliada es ampliar el universo cultural de los niños y niñas ofreciéndoles diferentes posibilidades para participar en actividades relacionadas al arte, el juego, el deporte y las nuevas tecnologías. Promover encuentros con los contenidos curriculares a través de múltiples lenguajes.

En el marco de la Jornada Ampliada, se promueve el Programa de Pedagogía Emprendedora. La metodología de este programa consiste en que los y las docentes junto a sus estudiantes se interroguen a sí mismos en relación a su sueño individual. Una vez identificados estos sueños individuales, se elige en forma 
democrática un sueño que se considerará desde ese momento como el sueño colectivo. De allí en más, cada uno de los individuos aportará tiempo y esfuerzo al logro del sueño colectivo que podrá subdividirse en metas y sub-objetivos. Para desarrollar este programa el Ministerio de Educación brinda capacitación a docentes, una plataforma virtual11 para comunicación permanente y un recurso en formato papel (colección de cuadernillos), que contiene actividades para estimular la participación de los estudiantes en la propuesta. Las actividades remiten a la interrogación individual, al deseo propio de cada estudiante, en el marco de la institución escolar a la que asiste y del barrio de la ciudad que habita ${ }^{12}$.

\section{El recurso didáctico}

\subsection{Concepto de dispositivo}

El concepto de dispositivo en "Va de vuelta": es el conjunto de elementos materiales y de técnicas que se conjugan creando una atmósfera, abriendo un espacio-tiempo que permite a los sujetos que la habitan navegar en los símbolos que distinguen a una misma comunidad. Esto favorece que en cada individuo emerjan las emociones que hacen posible la apropiación de esos mismos símbolos compartidos con su comunidad. (Banchoff, Vazquez, Martin, Harari, 2016, p.292)

\section{2 ¿Qué es "Va de Vuelta"?}

"Va de Vuelta" es un recurso didáctico, que presenta una historia desplegada a través de múltiples medios y plataformas de comunicación (transmedia) narrada en tres capítulos. El primer capítulo de "Va de Vuelta" propone una solución a la incorporación de tecnología digital en ámbitos educativos, ofreciendo un producto cuya estética visual y dinámica interactiva es sumamente atractiva para los niños y niñas usuarios. A su vez, favorece a los y las docentes la incorporación de un objeto digital creado desde el punto de vista educativo. Favorece habitar y permanecer en ámbitos físicos (aula de clases) y ámbitos digitales (videojuego) con similares valores éticos y morales. El primer capítulo se comunica en tres soportes distintos:

- un relato escrito e ilustrado, impreso en papel

- un juego de tablero físico confeccionado en tela (con una mecánica similar al juego de la oca)

- un juego de tablero digital (mini videojuego), descargable para teléfonos con sistema operativo Android) 


\section{3 ¿Cómo se usa?}

La implementación se realiza en tres etapas.

- En la primera etapa, el/la docente leerá el relato a los/las niños/as. Los/las docentes donarán su voz, estimulando en los niños/as la imaginación y la expresión artística: dibujo, pintura, cerámica, danzas, dramatizaciones.

- En la segunda etapa, el/la docente jugarán el juego de tablero físico, resolviendo los desafíos que propone cada casillero junto al grupo de niños/niñas a su cargo. Los desafíos consisten en actividades que estimulan el aprendizaje de la lecto-escritura. Esta etapa favorece la expresión oral, el trabajo en equipo y la convivencia respetuosa.

- Finalmente, en la etapa tres, los niños jugarán el juego de tablero digital (mini videojuego).En esta etapa se facilita la incorporación de tecnología digital en la institución educativa. La institución establecerá una jornada junto a las familias de los/las niños/as para jugar el juego de tablero digital (individualmente), de manera que cada familia jugará el mini videojuego con un niño/a, en un dispositivo digital (teléfono con sistema operativo Android). El tiempo programado en el tablero digital se limita a siete minutos por partida.

\subsection{Antecedentes 2013-2016}

En 2013, junto a siete jóvenes de quinto año de la Escuela Secundaria Orientada Nro. 518 "Carlos Fuentealba", redactamos los contenidos de una revista escolar que relataba la dinámica de paseos educativos que los jóvenes realizaron en el transcurso de los cinco años de estudios secundarios. Nos inspiramos en la Escuela Viva que desarrolló Olga Cossettini (Cossettini, 1942). Los jóvenes estudiantes compartían el objetivo de motivar a los estudiantes ingresantes a primer año de secundario, a continuar sus estudios hasta completar el nivel, en el quinto año. Se imprimió un ejemplar de la revista que llevó el nombre "Caminos" que se presentó en el Acto de Colación de los jóvenes egresados. La columna editorial está escrita en lengua española y lengua Qom.

Al año siguiente, 2014, la autora de "Va de Vuelta", presenta una propuesta de Revista Digital a las autoridades del Área de Cultura del Distrito Oeste de la Municipalidad de Rosario. Durante la creación de los contenidos de la revista digital, la autora comprendió que el mayor disfrute de los participantes se demostraba en las dramatizaciones y en los recreos, en los cuales los participantes eran libres de jugar videojuegos gratuitos en las computadoras que ocupaban para el taller de revista digital.

Para el año 2015, la autora de "Va de Vuelta" (vdv) estaba convencida de la potencia educativa de los videojuegos, por lo cual se dispuso a transformar el concepto de Revista Digital en un videojuego. Decidió la 
participación en el Mercado de Industrias Culturales $\operatorname{Argentinas~}^{13}$ (MICA), con el objetivo de vincularse con desarrolladores de videojuegos del Sector Videojuegos. En la edición de Setiembre de ese mismo año, vdv captó el interés del Ministerio de Ciencia, Tecnología e Innovación Productiva de la Nación, quien ofreció a vdv, postularse para recibir una ayuda económica que posibilite el desarrollo del videojuego. Para acceder a estos fondos de financiación era necesaria una planificación minuciosa que requería un plazo de redacción de un año de tiempo aproximadamente.

Comprendiendo que llegar a un videojuego era un camino sinuoso, "Va de Vuelta" recorrió numerosos eventos tanto del ámbito de los videojuegos, como del ámbito de los juegos de mesa (también llamados juegos de tablero). Así logra, en 2016, trabajar junto a la Cátedra de Seminario de Lenguajes de Programación, opción Python, correspondiente al segundo año de cursada de la carrera de Licenciado en Programación de la Universidad Nacional de La Plata. Buenos Aires, Argentina. Para tal efecto, su autora ya había comprendido la complejidad relativa a la redacción del Documento de Diseño de videojuegos, en el cual se escriben las indicaciones para el programador, el ilustrador y el músico de videojuegos. De los videojuegos desarrollados con software libre por cuatro grupos de estudiantes, se realizó una jornada de testeo junto a docentes del área Lengua y Literatura de sexto y séptimo grado de la Escuela Primaria Nro. 1358 "Macacha Guemes". La experiencia de juego junto a maestras de nivel primario, permitió comprender la importancia del atractivo estético al momento de presentar una propuesta audiovisual interactiva (videojuego) a los estudiantes.

Los resultados del trabajo realizado se comunicaron en el Congreso Internacional de Educación y Videojuegos (CIVE), organizado por la Facultad de Ciencias Sociales de la Universidad de Vigo, Pontevedra, España (Banchoff et al, 2016).

El recorrido realizado motivó la creación de la Productora de Servicios Educativos VDV en 2017, año en que decide su fundación y lanzamiento de su primer recurso didáctico para nivel inicial y primer ciclo de nivel primario, que como expresamos anteriormente, se compone de un relato impreso en papel, un juego de tablero físico y un mini videojuego descargable para teléfonos con tecnología Android.

"Va de vuelta" decide situarse en la cultura originaria qom, con la intención de ser compartida con los y las docentes de nivel inicial y primer ciclo de nivel primario de la ciudad de Rosario para conocer sus fortalezas y debilidades en el logro de sus objetivos: favorecer la transmisión de cultura identitaria, favorecer la convivencia respetuosa de la multiculturalidad en el aula de clases, y abordar la alfabetización digital de niños y niñas con los mismos valores éticos y morales con los cuales acordamos en sociedad. 


\section{La dimensión del vínculo entre los sujetos y el recurso didáctico}

\subsection{Red socio técnica.}

En el prólogo a la obra Cybercultura de Pierre Lévy, Manuel Medina menciona la distinción que realiza el autor al considerar de forma integral los conceptos de tecnología, cultura y sociedad. Explica que, para el autor, estos conceptos no existen separadamente, sino que cada uno de ellos es un componente relativo a los entornos donde se materializan producciones que implican tales conceptos. De allí que la cultura digital es el resultado de un sistema socio-técnico-cultural. Agrega que estos sistemas no son puros, sino que las prácticas culturales son híbridas, debido a que esa práctica cultural se encuentran articuladas y realizada socialmente, interpretada simbólicamente, situada ambientalmente y mediada-condicionada por artefactos tecnológicos (Levy, 2007).

La Dra. Griselda Guarnieri recupera el concepto de Red Socio-Técnica de Pierre Lévy. En su tesis doctoral "El modo interactivo del Dispositivo Hipermedial Dinámico", Enumera y describe seis principios del hipertexto. El cuarto principio es:

El principio de exterioridad: en la formación de una red socio-técnica se incluyen permanentemente elementos nuevos que no concernían a la misma, esta red de relaciones de inclusión/exclusión se da en forma permanente. Tanto el crecimiento como la disminución, su composición o recomposición dependen de un exterior indeterminado, incluir nuevos elementos, conectar con otras redes. (Guarnieri, 2010, p.93)

La experiencia lúdica que se propone VDV Productora de Servicios Educativos, en la Escuela Primaria "Nueva Esperanza" indaga sobre el vínculo que establecen las y los docentes de primer ciclo de nivel primario, en relación al recurso didáctico "Va de Vuelta". En este sentido, se busca conocer si los y las docentes se vinculan con el recurso integrándose a una red socio-técnica de producción de interculturalidad bilingüe.

\subsection{La experiencia en la Escuela Primaria "Nueva Esperanza"}

Las docentes se dispusieron a participar activamente en la experiencia lúdica. La autora presentó el recurso didáctico "Va de vuelta", invitándolas a transitar las tres etapas que la experiencia lúdica propone.

En el primer encuentro entre la autora y las docentes, se presentó el recurso "Va de vuelta" con sus tres soportes comunicacionales: un relato complementado con un juego de tablero físico y con un juego de tablero digital (mini videojuego). En el segundo se presentaron los objetivos del recurso didáctico y se acordaron los objetivos de la experiencia lúdica. En el tercer encuentro se desarrolló la experiencia lúdica. 


\subsubsection{Objetivo de la Experiencia lúdica}

- Presentar a las maestras de primer ciclo la propuesta de "Va de Vuelta"

- Vivenciar la experiencia lúdica que ofrece,

- Y Obtener sus devoluciones en relación a:

1. Los materiales utilizados en la presentación,

2. Así como la mecánica del juego,

3. La potencia lúdica que pueda proyectarse para el primer trimestre de 2018.

4. ¿Es posible alcanzar los objetivos (general y específico) con la propuesta de "Va de vuelta"?

6.2.2 Objetivo General de "Va de vuelta" situado en la Escuela EIB Nro. 1333 "Nueva Esperanza"

- Desarrollar y enriquecer un ambiente lúdico que facilite el proceso de enseñanza-aprendizaje.

\subsubsection{Objetivo Específico de "Va de vuelta" situado en la Escuela EIB Nro. 1333 "Nueva Esperanza"}

- Favorecer la expresividad verbal oral y escrita.

- Favorecer el acceso a la tecnología digital intercultural.

\section{Resultados}

De la experiencia lúdica realizada con las docentes de primer grado de la Escuela Primaria Nro. 1333 "Nueva Esperanza", de la ciudad de Rosario, la autora comprendió que es necesario realizar un sencillo replanteamiento de la presentación original.

La nueva propuesta incorpora un cuadernillo de actividades reemplazando el tablero físico de la segunda etapa de implementación del recurso didáctico presentado.

Tanto las docentes como la Vicedirectora recibieron con entusiasmo un recurso didáctico que pone 
en valor la cultura del Pueblo Originario Qom, a la vez que se presenta en distintos formatos que permiten articular distintas dinámicas de trabajo en el aula de clases.

\section{Discusiones}

Las docentes expusieron que el uso de un solo tablero físico para un grupo de veinte niños y niñas es insuficiente para mantener la atención y la convivencia respetuosa, que "Va de vuelta" se propone como objetivo. Así, luego de comprender que las docentes prefieren trabajar con figuras de papel recortables y una diversidad de materiales de dibujo y pintura, se decidió reemplazar el tablero físico por un cuadernillo de actividades organizadas en unidades temáticas para aplicar en el aula de clases. De esta forma, el cuadernillo de actividades aplicables en el aula de clases permite experimentar los lenguajes expresivos de pintura, dibujo, cerámica (entre otras), favoreciendo así la valoración de la cultura del Pueblo Originario Qom, por parte de los niños y las niñas rosarinos/as, a la vez que favorece a los niños y las niñas de familias del Pueblo Originario Qom la apropiación de sus valores culturales. Adicionalmente, y atendiendo a un rasgo característico de la comunidad qom, cada una de las actividades para aplicar en el aula de clases se planificarán con una breve evaluación.

\section{Conclusiones}

Como recurso didáctico en el ámbito de la educación intercultural bilingüe, "Va de vuelta" presenta la aventura de dos personajes de la comunidad qom, que nos mostrarán su cosmovisión en la forma de tres símbolos culturales potentes: el tigre que representará la fuerza y el orgullo, la lechuza que representará la sabiduría y la desobediencia y la serpiente que representará al conocimiento elevado de otros mundos y la ignorancia. La niña y el niño qom, que narran la aventura de su viaje a través del monte chaqueño hasta la ciudad de Rosario, llegarán para encontrarse con una persona de autoridad. Este encuentro se logrará luego de haber reconocido a lo largo de su viaje, que la fuerza del tigre también es su fuerza, así como la sabiduría de la lechuza y el conocimiento elevado de otros mundos habita en su corazón. El relato recupera los símbolos culturales del pueblo originario qom, para favorecer el proceso de enseñanza-aprendizaje de la lecto-escritura en español.

A su vez, los y las docentes que pertenecen a la cultura rosarina y que han sido formados en la importancia de la selección y creación de recursos didácticos para presentar los contenidos curriculares, encuentran en "Va de vuelta" un recurso innovador. Si bien existen en el mercado publicaciones destinadas a docentes de nivel inicial y primario, ninguna de ellas pone en valor el encuentro intercultural bilingüe, así como tampoco cuentan con recursos digitales fácilmente aplicables en educación. Tanto las publicaciones mencionadas, como los recursos audiovisuales, incluidos los videojuegos, requieren por parte de los y las docentes, una minuciosa adaptación curricular para lograr el objetivo pedagógico. 
"Va de vuelta" es el resultado de una intensa búsqueda de integración de lenguajes con estéticas y narrativas propias: los cuentos, los juegos, la tecnología digital. El proceso de cinco años de observación participante, en el cual se han creado y presentado a jóvenes, docentes, niños y niñas distintas propuestas de recursos que complementan objetos físicos con objetos digitales, ha llegado a su primera presentación: un recurso didáctico para abordar el proceso de enseñanza-aprendizaje de lecto-escritura y la alfabetización digital. Luego de haber transitado el difícil camino de integración de los intereses de tres dimensiones: la dimensión cultural, la dimensión institucional y la dimensión de los intereses de niños y niñas pertenecientes a dos culturas que se encuentran en una misma escuela, en una misma aula de clases.

El recurso didáctico presentado asume para sí, la responsabilidad de poner en valor los símbolos de dos culturas diferentes, favoreciendo la apreciación de la una respecto de a otra, habilitando la construcción de sentido identitario en el espacio-tiempo de educación formal.

"Va de vuelta" se presenta como un recurso didáctico capaz de organizar la red socio-técnica que lo interviene para nutrirlo de sentido. Las docentes que han participado de la experiencia lúdica en la Escuela Intercultural Bilingüe Nro. 1333. "Nueva Esperanza”, han expresado la bienvenida a un recurso que han co-creado, que han intervenido, que ha favorecido la expresión de sus necesidades y sus intereses como educadoras, a la vez que lo seleccionan e intervienen en el mismo ámbito donde lo implementarán. Consecuentemente se han establecido los acuerdos necesarios para elaborar los indicadores que permitirán avanzar en una investigación que logre abordar los aspectos cuantitativos no abarcados en el presente trabajo.

De esta manera, luego de haber comprendido que el contraste entre las dos culturas abarcadas dificulta en los niños y niñas qom el aprendizaje de la lecto-escritura en español, "Va de vuelta" ofrece una nueva manera de habitar los espacios físicos y abordar los espacios digitales. Esto es, una manera situada, en un espacio-tiempo de convivencia respetuosa en un ámbito educativo social y culturalmente inclusivo.

\section{Referencias}

1 Sitio web de la Municipalidad de Rosario. Secretaría de Cultura y Educación. Recuperado de: https://www.rosariocultura.gob.ar/

2 Sitio web del Ente Turístico de Rosario. Recuperado de: http://www.rosarioturismo.com/es/

3: Sitio web del Club Remeros Alberdi. Deportes. Remo. Recuperado de: http://www.clubremerosalberdi.com.ar/index.php?url_amigable=remo

4 Gracía, M (2013) Creatividad e ingenio: Entrevista a Chiqui González . Aptus Propuestas Educativas. Recuperado de: http://www.aptus.com.ar/creatividad-e-ingenio-entrevista-a-chiqui-gonzalez/

5 Sitio web Municipalidad de Rosario. www.rosario.gov.ar. Tríptico de la Infancia.

La isla de los Inventos. Recuperado de: 
http://www.rosario.gov.ar/web/ciudad/cultura/centros-culturales/la-isla-de-los-inventos

La Granja de la Infancia. Recuperado de:

http://www.rosario.gov.ar/web/ciudad/cultura/centros-culturales/la-granja-de-la-infancia

El Jardín de los niños. Recuperado de:

https://www.rosario.gov.ar/web/ciudad/cultura/centros-culturales/el-jardin-de-los-ninos

6 En Rosario viven 30.000 indígenas que buscan ganarse un lugar en la ciudad (2009) La Capital. Recuperado de: https://www.lacapital.com.ar/la-ciudad/en-rosario-viven-30000-indiacutegenas-que-buscan-ganarse-un-lugar-laciudad-n312436.html

7 Ministerio de Educación de la Provincia de Santa Fe. Resolución Nro. 1188, emitido 29 de Junio de 2017.

8 Ley 26.206 (2006) Ley de Educación Nacional. Recuperado de:

http://www.inet.edu.ar/index.php/institucional/normativa/ley-de-educacion-nacional/

9 Sitio web del Gobierno de la Provincia de Santa Fe. Jornada Ampliada. Recuperado de: https://www.santafe.gov.ar/index.php/web/content/view/full/190727

10 Sitio web del Gobierno de la Provincia de Santa Fe. Calidad Educativa. Recuperado de https://www.santafe.gov.ar/index.php/educacion/guia/get_tree_by_node?node_id=103804

11Sitio web del Gobierno de Santa Fe. Campus Educativo. Recuperado de:

http://campuseducativo.santafe.gob.ar/programa-pedagogia-emprendedora/

12 Pedagogía emprendedora (12 de Julio de 2016). Recuperado de:

https://www.youtube.com/watch?v=seqtSPuUd0Y

13 Sitio web del Ministerio de Cultura. Presidencia de la Nación. Mercado de Industrias Creativas Argentinas. Recuperado de:

https://mica.cultura.gob.ar/

Banchoff, Vazquez, Martin \& Harari (2016). Va de vuelta: Dispositivo Lúdico Educativo para abordar la alfabetización digital de niños y niñas. Legerén-Lago, B \& Crespo-Pereira, V (eds.) De la Idea a la Pantalla-Compendio de Investigaciones sobre Juegos Serios (pp.290-303). Pontevedra, España.: Universidad de Vigo. ISBN: 978-84-617-5940-8 Recuperado de: https://cive2016creas2i.files.wordpress.com/2017/06/delaideaalapantalla-disencc83o-de-juegos-serios.pdf

Bigot, Margot (2007) Los aborígenes Qom en Rosario: contacto lingüístico-cultural, bilingüismo, diglosia y vitalidad etnolingüística en grupos de aborígenes qom tobas asentados en Rosario- $1^{\text {a }}$ ed. Rosario, Argentina: UNR Editora. Universidad Nacional de Rosario. ISBN 978-950-673-607-1.

Bloj, A. (2009) El revés del reino: Experiencia de investigación. La literatura infantil como recurso subjetivante. Rosario, Argentina: Laborde Editor. ISBN 978-987-1315-55-0.

Canal Encuentro (2007) Pueblos Originarios/Qom-Tobas I: Somos del monte. Recuperado de http://encuentro.gob.ar/programas/serie/8008/244

Cordeu, E.J. (1969) Aproximación al Horizonte Mítico de los Tobas. Recuperado de: 
http://pueblosoriginarios.com/textos/cordeu/tobas.html

Cossettini, O. (1942) La Escuela Viva. Buenos Aires, Argentina: Editorial Lozada S.A

Guarnieri, G. (2010) El modo interactivo del Dispositivo Hipermedial Dinámico. (Tesis de doctorado. Universidad Nacional de Rosario. Rosario, Argentina). ISBN 978-987-26926-0-5. Recuperado de:

http://rephip.unr.edu.ar/bitstream/handle/2133/1741/Tesis\%20Guarnieri\%20Version\%20Final2.pdf?sequence=6

Levy, P (2007) Cyberculura. La cultura de la sociedad digital. Universidad Autónoma Metropolitana, Méjico: Anthropos Editorial. ISBN 978-II4-7658_8GS-6

Pérez Serrano, G (1994) Investigación cualitativa. Retos e interrogantes. Tomo I Métodos. Buenos Aires, Argentina: Editorial La Muralla S.A. ISBN: 9788471336286

Traversa, O. (s/f) Aproximaciones a la noción de dispositivo Recuperado de: http://www.fba.unlp.edu.ar/medios/biblio/2016-Traversa-Aproximaciones-a-La-Nocion-de-Dispositivo.pdf

Vazquez, MR (2014) Espacio de Aprendizaje Concurso Viva la Lectura organizado por el Ministerio de Educación de la Nación y la Organización de Estados Iberoamericanos. Auspiciado por la Fundación Santillana. Recuperado de: http://www.ineverycrea.com.ar/comunidad/ineverycreaargentina/recurso/espacio-de-aprendizaje2/149e7ab9-8418-4f7d$889 \mathrm{~b}-843 \mathrm{c} 6534 \mathrm{a} 071$

\section{Agradecimientos}

La Experiencia Lúdica propuesta por VDV, ha sido posible gracias al entusiasmo y la generosidad de la Sra. Vicedirectora de la Escuela Primaria Nro. 1333 "Nueva Esperanza”, Prof. Verónica Pavone. El agradecimiento se extiende a las docentes de primer grado de la misma escuela que han participado activamente, realizando valiosos aportes al desarrollo de VDV. El encuentro con la Escuela "Nueva Esperanza" ha sido favorecido por la Sra. Directora de la Escuela Secundaria Orientada en Humanidades y Ciencias Sociales, Nro. 518 "Carlos Fuentealba”, recientemente incorporada a la Modalidad Intercultural Bilingüe, Prof. Stella Maris Pérez. La comprensión por parte de la autora de VDV, de la complejidad que abarca el encuentro multicultural en el aula de clases, ha sido propiciada por el Prof. De Artesanía Qom, Prof. Juan Cudutti, referente y representante activo del Pueblo Originario Qom.

"Toda producción de sentido, en efecto, tiene una manifestación material”.

Verón, citado por Traversa. 